\title{
The Clinical Inadequacy of the Placebo Model and the Development of an Alternative Conceptual Framework
}

\author{
Giovanni A. Fava ${ }^{a}$ b Jenny Guidi ${ }^{a}$ Chiara Rafanelli $^{a}$ Karl Rickels ${ }^{c}$ \\ ${ }^{a}$ Department of Psychology, University of Bologna, Bologna, Italy; ${ }^{b}$ Department of Psychiatry, State University of \\ New York at Buffalo, Buffalo, NY, and ' Department of Psychiatry, University of Pennsylvania, Philadelphia, PA, USA
}

\section{Keywords}

Placebo · Drug treatment · Psychotherapy $\cdot$ Illness behavior - Self-management - Treatment setting ·

Tolerance $\cdot$ Evidence-based medicine

\begin{abstract}
Placebo effects are often attributed to clinical interactions and contextual factors that affect expectations of the patient about the treatment and result in symptom changes. The prevailing conceptualization consists of an undifferentiated placebo response that needs to be minimized in controlled investigations and maximized in clinical practice. However, treatment outcome is the cumulative result of the interaction of several classes of variables with a selected treatment: living conditions (housing, nutrition, work environment, social support), patient characteristics (age, sex, genetics, general health conditions, personality, well-being), illness features and previous therapeutic experience, self-management, and treatment setting (physician's attitude and attention, illness behavior). Such variables may be therapeutic or countertherapeutic, and are unlikely to be simply additive. In certain patients their interactive combination may lead to clinical improvement, whereas in other cases it may produce no effect, and, in a third group, it may
\end{abstract}

\section{KARGER}

(C) 2017 S. Karger AG, Basel

E-Mail karger@karger.com

www.karger.com/pps lead to worsening of the condition. Maximizing patients' expectations does not necessarily result in sustained effects and, in due course, may actually lead to worsening of the condition (violation of expectations). In this paper, we outline a multifactorial conceptual model that may have implications for the design of clinical trials as well as for clinical practice, with special reference to psychopharmacology and psychotherapy. The effects of drug treatment may be potentiated by specific nonpharmacological treatment strategies, and this synergism may disclose significant differences against placebo. Medical outcomes may be unsatisfactory not because technical interventions are missing, but because our conceptual models and thinking are inadequate.

(c) 2017 S. Karger AG, Basel

\section{Introduction}

The mechanisms of the placebo effect in medical and psychological therapies have been an endless source of debate. A recent comprehensive review of placebo responses [1] suggested that they are mediated by expectations, associative learning processes, and the quality of the patient-physician interaction. These components

Giovanni A. Fava, MD

Department of Psychology, University of Bologna Viale Berti Pichat 5

IT-40127 Bologna (Italy)

E-Mail giovanniandrea.fava@ unibo.it 
modulate, through complex neurobiological mechanisms, symptom perception, the course of diseases, and the efficacy and tolerability of medical treatment [1]. Placebos may yield positive, negative, or no effects. As complex is their likelihood of inducing side effects, which are often subsumed under the rubric of nocebo effects [1]. It is virtually impossible to administer an active treatment without placebo components [2]. In a randomized controlled trial, the difference between the response of patients randomized to the tested treatment and of patients randomized to placebo constitutes the specific effect. If the mean reduction of symptoms is $50 \%$ in patients receiving an antidepressant drug and $30 \%$ in patients randomized to placebo, then the true drug effect is $20 \%$. The implicit assumption is that of an additive model [3]. The placebo response has appeared to have grown over the years, and this has been particularly impressive in clinical trials concerned with psychiatric disorders [4]. Not surprisingly, what is then advocated is to minimize the placebo effect in trials to ensure that the efficacy of the investigational treatment can be truly evaluated [2]. Trial designs can thus attempt to minimize the placebo effects [2], as with the sequential parallel comparison design for double-blind placebo-controlled trials in psychiatric disorders [4]. Once the efficacy of the treatment is established by double-blind placebo-controlled trials, placebo effects should be maximized by stimulating the patients' expectations [2]. Linden [5] has recently summarized such an approach: inducing hope and optimism ("everything will be fine"), helping the patient look for improvement, and, even if the therapist feels unsure about the prognosis, telling that this is the best treatment available. Several lines of research, however, may call this oversimplified model in question.

\section{Treatment Outcome as a Multifactorial Product}

The fact of lumping together all possible factors that may modulate the therapeutic response under the placebo umbrella is questionable [6]. Patients receiving placebos in clinical trials or practice may improve for a variety of reasons other than any causal connection between the placebo and the outcome [7]. Diagnostic misclassification, inclusion/exclusion criteria, spontaneous remission, the natural course of symptoms, regression to the mean in repeated measurements, study design issues, measurement error or poor sensitivity, and high attrition may all affect therapeutic results in clinical trials $[4,6]$. Wolf $[8]$ equated placebo to "any effect attributable

Placebo Model to a pill, potion or procedure, but not to its pharmacodynamics or specific properties" (p. 689). Accordingly, in the context of drug therapy, these effects were equivalent to "nondrug," even though it was acknowledged that nonspecific variables could have specific effects [9]. They derive from the significance to the patient of the whole situation surrounding the therapeutic effort [8], such as expectations [10]. However, in clinical trials they may also stem from the use in both arms of therapeutic ingredients that may increase effectiveness. Walach [11], reviewing the placebo effects in complementary and alternative medicine, underscored the derogatory connotation of the word "nonspecific" as opposed to the pharmacological god of specificity. Labeling a therapeutic ingredient as nonspecific may lead to underestimation of its role as a minor, optional element of the therapy. Is a change in lifestyle that is likely to yield clinical benefits a random nonspecific event or the result of specific interactions and efforts? In a series of studies started in the late fifties and conducted jointly by the NIMH Psychopharmacology Service Center, the University of Pennsylvania, and Johns Hopkins University [9], interventions that would be labeled as nonspecific (such as the physician's attitude) were compared in controlled studies, and significant differences were disclosed. Further, several interactions were found between allegedly specific and nonspecific effects. Rickels [9] summarized such contributions in a model that is updated and expanded here (Fig. 1). According to this model, treatment outcome is the cumulative result of the interaction of several classes of variables with a selected treatment as described in the following.

\section{Living Conditions}

Housing, nutrition, work environment, and social support may all affect the quality and characteristics of treatment response [12]. For instance, an antibiotic that is used against tuberculosis in adverse environmental conditions (e.g., bad housing and heating, insufficient nutrition) is unlikely to yield the same results as when the drug is used in optimal living conditions.

\section{Patient Characteristics}

A considerable amount of initial research on placebo has been devoted to the search of the placebo reactor, indicating some enduring characteristics of the individual receiving therapy, such as demographic variables, personality, or suggestibility [13]. The landmark studies of Lasagna et al. [14, 15], however, soon clarified that the same patient may display a placebo reaction in one ex-

Psychother Psychosom 2017;86:332-340 DOI: $10.1159 / 000480038$ 


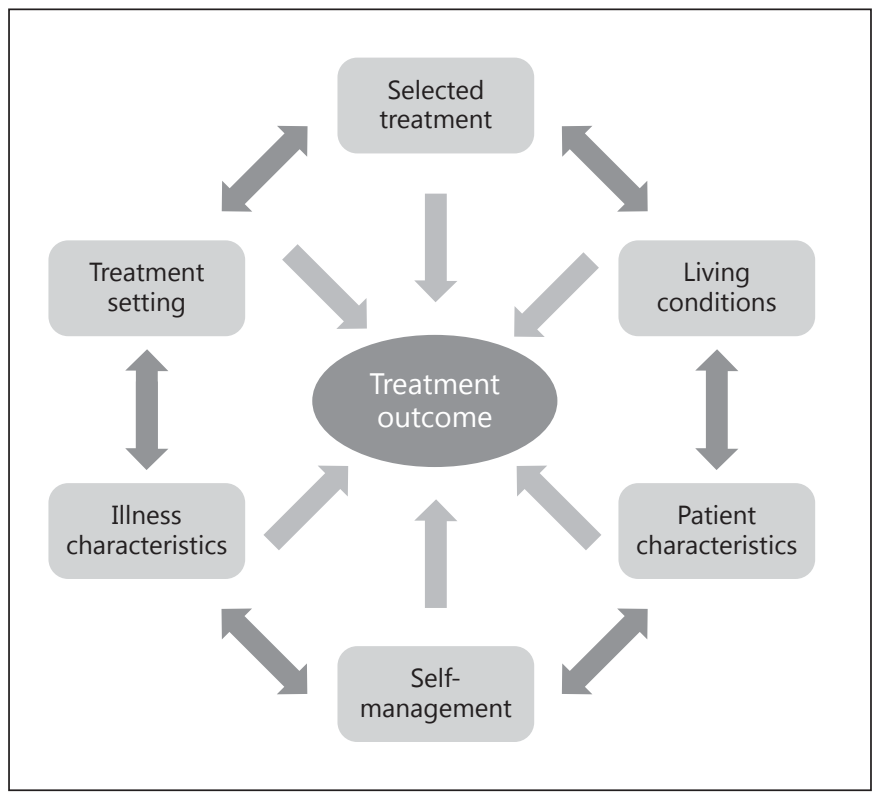

Fig. 1. Interacting therapeutic variables affecting treatment outcome.

perimental set and not in another, casting doubts on the view of a consistent placebo reactor. Certain predispositions become associated with placebo reactivity only in certain situations $[13,16]$. Similar considerations may apply to the search for genetic biomarkers of a placebo response $[1,17]$.

\section{Self-Management}

The role of the patient in collaborating with the treatment plan (self-management) has been found to be of paramount importance in several medical diseases, such as diabetes and cardiovascular illness [18]. Statins may decrease cholesterol levels, but their interactions with behavioral factors may modulate their efficacy in the individual case. If statins are associated with appropriate health behavior, their effects may be enhanced, but if the patient, because of the introduction of a cholesterol-lowering drug, believes that he/she can eat anything and stops exercising, their effects may be neutralized or even yield worse outcomes. Similarly, if a patient who has agoraphobic avoidance and panic and is given an antipanic agent does not use the decrease in anxiety for exposing himself/herself to the feared situations, the effects of the drug may be minimal. Unfortunately, there have not been many clinical trials studying the interaction between drugs and self-management with a factorial design. A landmark exception has been the study by Marks et al.
[19], who evaluated the antiobsessive effects of clomipramine in association with self-management involving exposure or antiexposure.

\section{Illness Characteristics and Previous Treatments}

Duration of illness is a well-known variable affecting therapeutic response [9]. However, just as important is the previous treatment experience $[20,21]$. A trial with an antibiotic today is obviously different from a trial 40 years ago, when the use of antibiotics was not so widespread and the problem of resistance was not as prevalent [22]. Yet, it is astonishing how similar problems are ignored in psychotropic drug trials. Currently, 1 out of 6 adults in the USA is taking psychotropic drugs, in the majority of cases for long-term use [23]. Various forms of tolerance (e.g., resistance upon rechallenge, loss of clinical effect) and dependence may occur with the drugs and are likely to affect treatment response [24-28]. Very seldom, however, such clinical events are considered for including patients in a trial [29]. Designs that use highly heterogeneous populations of "nowhere patients" [30], characterized by resistance to a standard treatment at the start, follow an oversimplified conceptual model that clashes with the clinical reality they would attempt to mimic [31]. Clinical trials in psychopharmacology that neglect the issue of tolerance to previous treatments are at best useless and at worst misleading.

\section{Treatment Setting}

There is extensive evidence, which mostly derives from studies performed in the fifties and sixties by Rickels and associates $[9,32]$, that the situation in which therapy is administered is an important variable in its effectiveness. Patients may improve simply because they are placed in places that are symbols of competent care [33], as the study by Park and Covi [34], in which patients were told they were given placebos and yet improved, indicates. Such a study has recently been replicated [35]. In specific settings, only the interested and enthusiastic physician obtained significant improvement with active drugs compared with placebo, whereas the physician's lack of interest did not yield such differences [36, 37]. A new therapy whose indications, contraindications, and side effects are not fully appreciated is likely to elicit a greater intellectual and emotional investment of the physician, and this partially explains the success of novel treatments [13]. Psychotherapeutic research has disclosed therapeutic ingredients common to different approaches that are relevant to any patient-physician relationship, such as full availability of the therapist for 
specific times, opportunity for the patient to ventilate thoughts and feelings, an emotionally charged, confiding relationship with a helping person, a plausible explanation of the symptoms and side effects, the active participation of the patient in a procedure that is believed by both to be a means of restoring patient health [38-40]. Treatment setting ultimately modulates illness behavior [38], defined as "the varying ways individuals respond to bodily indications, how they monitor internal states, define and interpret symptoms, make attributions, take remedial actions and utilize various sources of informal and formal care" [41]. In the past decades, new lines of research have been concerned with illness perception, attendance at medical facilities, health care seeking behavior and treatment adherence [42]. Unfortunately, there has been very little research on monitoring the changes in illness behavior during treatment trials [43].

\section{Therapeutic and Countertherapeutic Treatment Ingredients}

Engel [44] outlined how the biopsychosocial model is needed to explain the number of variables operating in therapeutic encounters, such as the behavior of the physician and the relationship between the patient and the physician: "...the successful application of rational therapies is limited by the physician's ability to influence and modify the patient's behavior in directions concordant with health needs" [44, p. 132]. Despite evidence supporting the influence of context on health outcomes [45], the current emphasis on evidence-based-medicine is likely to concentrate on a single factor that differentiates drug from placebo and to neglect other variables [46, 47]. These latter variables are then subsumed under the reductionistic undifferentiated rubric of placebo. Miller and Kaptchuk [6] suggested that need of reconceptualizing the placebo effect with the term "contextual healing," with particular reference to the clinical encounter. "Attention to contextual healing signifies that there is more to medicine than diagnosing disease and administering proven effective treatments" [6, p. 224]. Certain treatment ingredients may be specific in one context (e.g., exposure to feared situations in case of phobic avoidance) and nonspecific in another (exposure in the absence of phobic avoidance). Further, the notion of nocebo effects fails to differentiate the appearance of side effects in patients who are assigned to placebo in a treatment trial from the worsening of symptomatology following placebo administration. Side effects may reflect dissatisfaction

Placebo Model with treatment and indirect hostility [48] and may correlate with pretreatment complaints and illness severity [49]. They are not necessarily negative, since they tend to occur also in patients who have improved [50]; they may facilitate remission in some patients, possibly by giving a signal that treatment is working. This is substantially different from the fact that a certain percentage of patients given placebos in various studies report their condition to be worsened $[13,51]$. As a result, treatment ingredients may also be countertherapeutic. For instance, the fact that significant differences between drug and placebo may occur with an empathic and encouraging, but not with a detached, physician may be due to some countertherapeutic ingredients that the latter introduces.

\section{Additive versus Interactive Models}

In 1964, Fisher et al. [52] challenged the assumption that drug-specific and nonspecific variables are simply additive in their combined effect. A particularly appropriate set may potentiate a given drug response, and, conversely, an unfavorable set may indeed inhibit drug action.

In a simple additive model, the ultimate behavioral response is always predictable from the simple sum of the two independent effects; if a favorable milieu is capable of producing a certain amount of improvement in placebo subjects, and the drug also has a favorable effect, then the sum of these two effects determines the outcome. In the interactive model, however, the outcome is not predictable simply from knowing what the drug and the set effects may be independently [52, pp. 150-151].

Such a conceptualization, which was allegedly inspired by clinical experience [52], was tested in a number of controlled trials [9]. Indeed, a clinician who uses the same drug in a number of cases who share the same clinical diagnosis may observe a wide range of responses (full response/partial response/no response/worsening). Such an occurrence reflects the fact that, in clinical trials where differentiation according to cogent subgroups is made, a treatment which is helpful on average may be ineffective in some patients (no difference with placebo) and even harmful in someone else (worse than placebo) $[53,54]$. For instance, in psychiatric practice one can observe that certain types of patients seem to antagonize drug effects, whether this is due to psychological reactance (a motivational force that leads individuals to fear loss of control), the balance between internal and external health control beliefs, and illness behavior [55]. Such paradoxical clinical phenomena can be easily found in the setting of personal-

Psychother Psychosom 2017;86:332-340 
Fig. 2. Models of effects of 2 therapeutic treatments combined (modified from Uhlenhuth et al. [57]). A, Pharmacotherapy; B, psychotherapy.
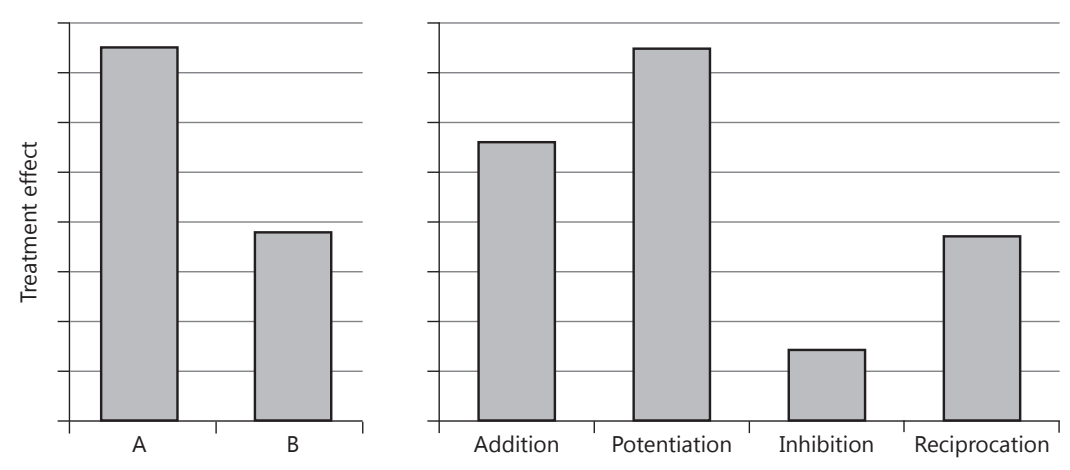

in addition to attention to well-known factors that may affect results (diagnostic accuracy, inclusion/exclusion criteria, lack of sensitivity of outcome measures, quality of data entry and verification, waxing and waning of the natural course of illness, regression to the mean phenomenon, high attrition) [4], the conceptual framework described in Figure 1 calls for close attention to additional variables, such as patient self-management and illness behavior. These variables are obscured by mixing them all under the placebo umbrella. As to psychotherapeutic trials, it is thus important to list all the potential treatment ingredients, according to the available literature, that are included in each treatment protocol (whether experimental or control group).

Further, the current dichotomy between clinical trials (with placebo minimization with strategies that exclude participants based on pretreatment response to a mixture of ingredients subsumed under the label of placebo) and practice (with maximization of placebo responses) [2] is challenged. Trials often use strategies that selectively exclude participants based on pretreatment response to placebo with the assumption that the trial will show a larger drug-placebo difference. Systematically attempting to minimize placebo responses, however, has yielded conflicting results [17].

Maximizing the patient's expectations about treatment may indeed be dangerous. After an initial response to placebo, patients are likely to go back to the baseline condition, or, in some cases, carryover effects may ensue [14, 15] (Fig. 3). However, a third possibility exists: the patient may precipitate to a state that is worse than the initial one (Fig. 3). This might be due to "violation of expectation": patients may interpret unfulfilled expectations about therapy as an indication that their condition 
Fig. 3. The long-term course of placebo responses and the violation of expectation.

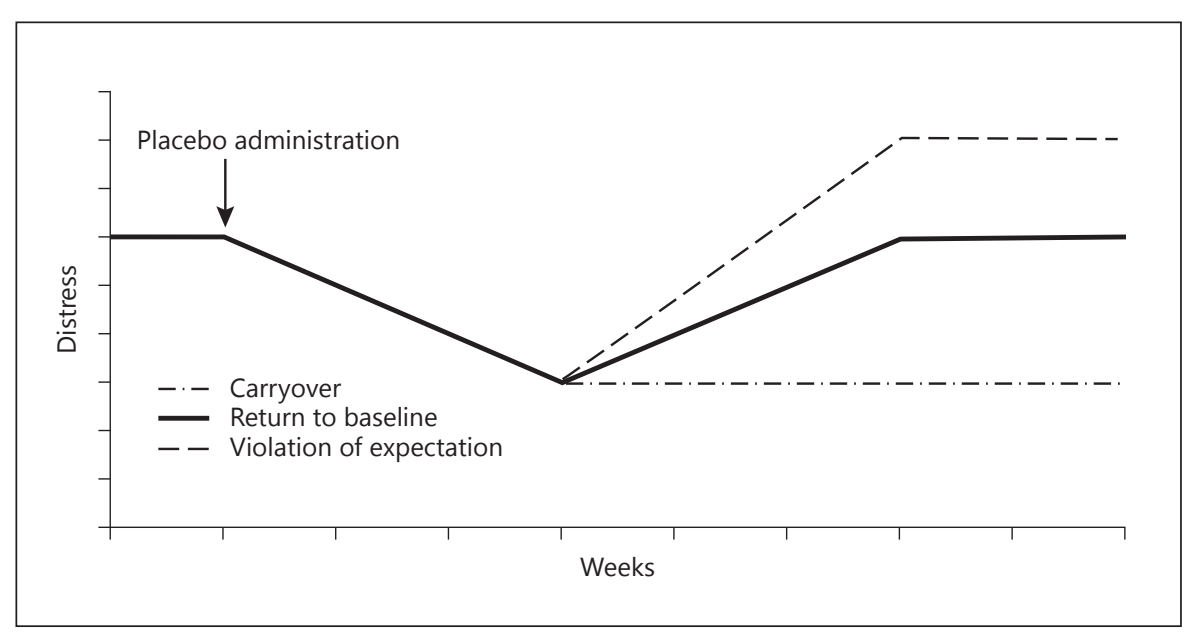

is untreatable [13]. Such phenomena may play a crucial clinical role in the occurrence of resistance: patients who unsuccessfully underwent various treatments may react to the failure of a new treatment with psychological disappointment and hopelessness. Drug treatment is likely to clash against such subjective responses that, properly addressed in randomized controlled trials, may differentiate experimental from control treatments.

Finally, the standard randomized controlled trial design is still based on the acute disease model. This is in sharp contrast with the fact that the patient is likely to have experienced other treatments before that may actually modify the clinical course and responsiveness [31]. The current standard therapeutic trial in psychopharmacology is represented by the large, multicenter, controlled randomized trial with broad inclusion criteria, and little attention to other factors such as the clinical history of the patient [30]. The heterogeneous features of these patients would then affect the outcome of the trial. An excessive nondrug treatment response, which contributes to poor differentiation of treatments, can be prevented by care in selecting study subjects, fewer study sites, and smaller sample sizes [59]. If a treatment is tested by a series of small trials with inclusion criteria for specific characteristics and attention to other potential therapeutic ingredients, we may have a better knowledge of its indications and contraindications [31]. There is an increasing need of expanding the clinimetric content of assessment $[60,61]$ by including staging [62], psychological well-being [63$65]$, mental pain $[66,67]$, and consideration of the number of patients who display deterioration in addition to improvement [68].

Placebo Model
A psychotherapeutic approach is likely to include multiple treatment ingredients [31, 69]. All potential treatment ingredients that were found to yield effects in controlled trials, whether they were labeled as nonspecific or common factors, should be detailed in the description of treatment packages of investigations concerned with psychotherapy. Finally, it has become common practice to quantify the number of subjects who, after a pharmacological and/or psychotherapeutic trial, achieve response or remission according to specific cutoff points of rating scales [31]. It is as important to indicate the number of subjects who display deterioration after treatment according to specific cutoff points of the same rating scales.

\section{Implications for Clinical Practice}

Unfortunately, overselling of drug or highly technological therapies induced by commercial propaganda has given the patient the misleading impression that a specific imbalance is the cause of his or her illness, that needs to be fixed by purely chemical means and that personal efforts and responsibility have no part to play in getting better [70]. In the same vein, the restrictive ideology that characterizes a prevalent reductionist practice of evidence-based medicine leads the clinician to disregard "nonspecific" ingredients as optional and uninfluential, often referring to the fact that "there is no evidence they work," against the clinical awareness that it is the sum of positive ingredients (incremental care) that often leads to improvement in practice. The physician who adheres to guidelines is convinced to apply the best evidence and to

Psychother Psychosom 2017;86:332-340 337 
be "scientific," and is not aware that he/she is simply guided to see problems in a certain way, to treat the average instead of the individual patient and to follow the pseudoscience of manipulated meta-analyses [47]. The goals of the randomized controlled trial may be different from those of a clinician. In the trial we want to find out as much as possible the extent of the contribution of the treatment under examination. The clinician wants to combine different effects in a meaningful way in order to potentiate the treatment outcome.

Today the clinician is driven to an overestimated consideration of potential benefits, paying little attention to the likelihood of responsiveness and to potential vulnerabilities in relation to the adverse effects of treatment [47, 71]. To counteract such detrimental treatment attitudes and overselling, when medications or other treatments are prescribed, it is important to point to minimize the patient's expectations (by telling for instance, that drugs may contribute, in the most optimistic hypothesis, to $50 \%$ of the total outcome, whereas the remaining part is up to patient self-management).

\section{Conclusions}

In psychiatry, as in the rest of medicine, the majority of patients have complex disorders, where comorbidity is the rule [60]. Further, any type of therapy, particularly after long-term use, may increase the risk of experiencing additional psychopathological problems that do not necessarily subside with discontinuation of treatment and may modify subsequent responsiveness [72]. Treatments are still believed to work by acting on a disease process, which translates into "curing" psychiatric diseases, even though a single course of treatment (whether pharmacotherapy or psychotherapy) is unlikely to entail solution to the disturbances of patients, both in research and clinical practice settings $[60,62,73]$.

We believe that many medical outcomes are unsatisfactory not because technical interventions are missing, but because our conceptual models and thinking are inadequate. This applies to both the methodology of clinical trials and the clinician's approach. If a physician disregards the importance of nondrug contributions and does not want to spend time with the patient for improving such contributions, the limitations of an isolated, magic bullet, reductionistic interventions are likely to emerge. The multifactorial ingredients of treatment outcome should become a part of both treatment trials and clinical approaches. In psychiatry drug treatment should be combined with specific nonpharmacological treatment strategies (e.g., structured self-management, modification of illness behavior) that may potentiate medication effects in disclosing significant differences against placebo. The issue of tolerance to previous treatments should also be considered. Similar considerations apply to controlled trials concerned with psychotherapy.

We call for a different conception of clinical trial whose aim is not the simple demonstration of statistical superiority of a treatment compared to control in a short-term study, but also the appraisal of differential interaction effects of multiple ingredients. The data that may originate from this type of clinical trials are closer to offer what a clinician needs for assessing treatment options in the individual case. These trials are unlikely to be supported by the private industry and call for a renewed interest by public funding agencies.

\section{Disclosure Statement}

The authors have no conflict of interest to disclose.

\section{References}

1 Schedlowski M, Enck P, Rief W, Bingel U: Neuro-bio-behavioral mechanisms of placebo and nocebo responses. Pharmacol Rev 2015;67:697-730.

2 Enck P, Bingel U, Schedlowski M, Rief W: The placebo response in medicine: minimize, maximize or personalize? Nature Rev 2013; 12:191-204.

3 Kirsch I: Are drug and placebo effects in depression additive? Biol Psychiatry 2000;4: 733-735.
4 Fava M, Evins AE, Dorer DJ, Schoenfeld DA: The problem of the placebo response in clinical trials for psychiatric disorders. Psychother Psychosom 2003;72:115-127.

5 Linden M: Placebo: unsolved problems for science, and simple conclusions for clinical practice. Am J Psychiatry 2017;174:91-92.

6 Miller FG, Kaptchuk TF: The power of context: reconceptualizing the placebo effect. J R Soc Med 2008;101:222-225.

7 Beecher HK: The powerful placebo. JAMA 1955;159:1602-1606.
8 Wolf S: The pharmacology of placebos. Pharmacol Rev 1959;11:689-704.

9 Rickels K (ed): Non-Specific Factors in Drug Therapy. Springfield, Thomas, 1968.

10 Price DD, Finniss DG, Benedetti F: A comprehensive review of the placebo effect. Annu Rev Psychol 2008;59:565-590. 
11 Walach H: Placebo effects in complementary and alternative medicine: the self-healing response; in Colloca L, Flaten MA, Meissner K (eds): Placebo and Pain. From Bench to Bedside. Amsterdam, Academic Press, 2013, pp 189-202.

12 Roy R: Social Support, Health and Illness. Toronto, University of Toronto Press, 2011.

13 Shapiro AK, Morris LA: The placebo effect in medical and psychological therapies; in Garfield SL, Bergin AE (eds): Handbook of Psychotherapy and Behavior Change. New York, Wiley, 1978, pp 369-410.

14 Lasagna L, Mosteller F, von Felsinger J, Beecher HK: A study of the placebo response. Am J Med 1954;16:770-779.

15 Lasagna L, Laties VG, Dohan JL: Further study on the pharmacology of placebo administration. J Clin Invest 1958;37:533-537.

16 Rickels K: Psychopharmacologic agents. J Nerv Ment Dis 1963;136:540-549.

17 Hall KT, Kaptchuk TJ: Genetic biomarkers of placebo response: what could it mean for $\mathrm{fu}$ ture trial design? Clin Investig 2013;3:311314.

18 Bodenhemier T, Lorig K, Holman H, Grumback K: Patient self-management of chronic disease in primary care. JAMA 2002;288: 2469-2475.

19 Marks IM, Lelliott P, Basoglu M, Noshirvani H, Monteiro W, Cohen D, Kasvikis Y: Clomipramine, self-exposure and therapist-aided exposure for obsessive-compulsive rituals. Br J Psychiatry 1988;152:522-534.

20 Rickels K, Downing RZ, Howard K: Predictors of chlordiazepoxide response in anxiety. Clin Pharmacol Ther 1971;12:263-273.

21 Downing RW, Rickels K: Predictors of amitriptyline response in outpatient depressives. J Nerv Ment Dis 1972;154:248-263.

22 Levy SB: The Antibiotic Paradox: How Miracle Drugs Are Destroying the Miracle. New York, Plenum Press, 1992.

23 Moore TJ, Mattison DR: Adult utilization of psychiatric drugs and differences by sex, age and race. JAMA Intern Med 2017;177:274275.

24 Fava GA, Offidani E: The mechanisms of tolerance in antidepressant action. Progr Neuropsychopharmacol Biol Psychiatry 2011;35: 1593-1602.

25 Chouinard G, Chouinard V-A: New classification of selective serotonin reuptake inhibitor withdrawal. Psychother Psychosom 2015; 84:63-71.

26 Starcevic V, Brakoulias V, Viswasam K, Berle $\mathrm{D}$ : Inconsistent portrayal of medication dependence, withdrawal and discontinuation symptoms in treatment guidelines for anxiety disorders. Psychother Psychosom 2015;84: 379-380.

27 Chouinard G, Samaha AN, Chouinard V-A, Peretti C-S, Kanahara N, Takase M, Iyo M: Antipsychotic-induced dopamine supersensitivity psychosis. Psychother Psychosom 2017;86:189-219.
28 Fava GA, Tomba E, Bech P: Clinical pharmacopsychology: conceptual foundations and emerging tasks. Psychother Psychosom 2017; 86:134-140.

29 Fava M, Mischoulon D, Iosifescu D, Witte J, Pencina M, Flyinn M, Harper L, Levy M, Rickels K, Pollack M: A double-blind placebo-controlled study of aripiprazole adjunctive to antidepressant therapy among depressed outpatients with inadeqate response to prior antidepressant therapy (ADAPT-A Study). Psychother Psychosom 2012;81:8797.

30 Tomba E: Nowhere patients. Psychother Psychosom 2012;81:69-72.

31 Fava GA, Tomba E, Tossani E: Innovative trends in the design of therapeutic trials in psychopharmacology and psychotherapy. Prog Neuropsychopharmacol Biol Psychiatry 2013;40:306-311.

32 Downing RW, Rickels K: Nonspecific factors and their interaction with psychological treatment in pharmacotherapy; in Lipton MA, DiMascio A, Killam KF (eds): Psychopharmacology: A Generation of Progress. New York, Raven Press, 1978, pp 1419-1427.

33 Gliedman CH, Nash EH, Huber SD, Stone AR, Frank JD: Reduction of symptoms by pharmacologically inert substances and by short-term psychotherapy. AMA Arch Neurol Psychiatry 1958;79:345-351.

34 Park LC, Covi L: Non-blind placebo trial. Arch Gen Psychiatry 1965;12:336-345.

35 Schaefer M, Harke R, Denke C: Open-label placebos improve symptoms in allergic rhinitis. Psychother Psychosom 2016;85:373-374.

36 Uhlenhuth EH, Canter A, Neustadt JO, Payson HE: The symptomatic relief of anxiety with meprobamate, phenobarbital and placebo. Am J Psychiatry 1959;115:905-910.

37 Uhlenhuth EN, Rickels K, Fisher S, Park LC, Lipman RS, Mock J: Drug, doctor's verbal attitude and clinic setting in the symptomatic response to pharmacotherapy. Psychopharmacologia 1966;9:392-418.

38 Fava GA, Cosci F, Sonino N: Current psychosomatic practice. Psychother Psychosom 2017;86:13-30.

39 Lambert MJ: Maximizing psychotherapeutic outcome beyond evidence-based medicine. Psychother Psychosom 2017;86:80-89.

40 Zilcha-Mano S, Roose SP, Barber JP, Rutherford BR: Therapeutic alliance in antidepressant treatment: cause or effect of symptomatic levels? Psychother Psychosom 2015;84: $177-182$.

41 Mechanic D: Sociological dimensions of illness behavior. Soc Sci Med 1995;41:12071216.

42 Sirri L, Fava GA, Sonino N: The unifying concept of illness behaviour. Psychother Psychosom 2013;82:74-81.

43 Magelli C, Fava GA, Grandi S, Semprini F, Bassein L, Capelletti D, Trombini G, Magnani B: Illness attitudes of patients suffering from mild heart failure during a pharmacological trial. Med Sci Res 1988;16:239-240.
44 Engel GL: The need for a new medical model: a challenge for biomedicine. Science 1977; 196:129-136.

45 Di Blasi Z, Harkness E, Ernst E, Georgiou A, Kleijnen J: Influence of context effects on health outcomes. Lancet 2001;357:757-762.

46 Fava GA, Rafanelli C, Guidi J, Sonino N: The clinical inadequacy of evidence-based medicine and the need of a conceptual framework based on clinical judgment. Psychother Psychosom 2015;84:1-3.

47 Fava GA: Evidence-based medicine was bound to fail: a report to Alvan Feinstein. J Clin Epidemiol 2017;84:3-7.

48 Downing RW, Rickels K: Self-report of hostility and the incidence of side reactions in neurotic outpatients treated with tranquillizing drugs and placebo. J Consult Psychol 1967;31: 71-76.

49 Nelson JC, Jatlow PI, Quinlan DM: Subjective complaints during desipramine treatment. Arch Gen Psychiatry 1984;41:55-59.

50 Shapiro AK, Mike V, Barton H, Shapiro E: Study of the placebo effect with a self-administered test. Comp Psychiatry 1973;14:535548.

51 Wolf S, Pinsky R: Effect of placebo administration and occurrence of toxic reactions. JAMA 1954;155:139-141.

52 Fisher S, Cole JO, Rickels K, Uhlenhuth EH: Drug-set interaction: the effects of expectations on drug response in outpatients; in Bradley PB, Flugel F, Hoch PH (eds): Neuropsychopharmacology. Amsterdam, Elsevier, 1964, vol 3, pp 149-156.

53 Horwitz RI, Singer BH, Makuch RW, Viscoli CM: Can treatment that is helpful on average be harmful to some patients? J Clin Epidemiol 1996;49:395-400.

54 Horwitz RI, Hayes-Conroy A, Singer BH: Biology, social environment, and personalized medicine. Psychother Psychosom 2017;86: 5-10.

55 De las Cuevas C, de Leon J: Reviving research on medication attitudes for improving pharmacotherapy. Psychother Psychosom 2017; 86:73-79.

56 DiMascio A: Personality and variability of response to psychotropic drugs: relationship to "paradoxical" effects; in Rickels K (ed): NonSpecific Factors in Drug Therapy. Springfield, Thomas, 1968, pp 40-49.

57 Uhlenhuth EH, Lipman RS, Covi L: Combined pharmacotherapy and psychotherapy. J Nerv Ment Dis 1969;148:52-64.

58 Forand NR, de Rubeis RJ, Amsterdam JD: Combining medication and psychotherapy in the treatment of major mental disorders; in Lambert MJ (ed): Bergin and Garfield's Handbook of Psychotherapy and Behavior Change, ed 6. New York, Wiley \& Sons, 2013, pp 735-774.

59 Robinson DS, Rickels K: Concerns about clinical drug trials. J Clin Psychopharmacol 2000; 20:593-596. 
60 Fava GA, Rafanelli C, Tomba E: The clinical process in psychiatry: a clinimetric approach. J Clin Psychiatry 2012;73:173-184.

61 Bech P: Clinimetric dilemmas in outcome scales for mental disorders. Psychother Psychosom 2016;85:323-326.

62 Guidi J, Tomba E, Cosci F, Park SK, Fava GA: The role of staging in planning psychotherapeutic interventions in depression. J Clin Psychiatry 2017;78:456-463.

63 Fava GA, Bech P: The concept of euthymia. Psychother Psychosom 2016;85:1-5.

64 Hasler G: Well-being. An important concept for psychotherapy and psychiatric neuroscience. Psychother Psychosom 2016;85:255261.

65 Topp CW, Østergaard SD, Søndergaard S, Bech P: The WHO-5 Well-Being Index: a systematic review of the literature. Psychother Psychosom 2015;84:167-176.
66 Blasco-Fontecilla H, Baca-Garcia E, Courtet P, Garcia Nieto R, de Leon J: Horror vacui emptiness might distinguish between major suicide repeaters and non-major suicide repeaters. Psychother Psychosom 2015;84:117119.

67 De Leon J, Baca-Garcia E, Blasco-Fontecilla $\mathrm{H}$ : From the serotonin model of suicide to a mental pain model of suicide. Psychother Psychosom 2015;84:323-329.

68 Carvalho AF, Sharma MS, Brunoni AR, Vieta E, Fava GA: The safety, tolerability and risks associated with the use of newer generation antidepressant drugs. Psychother Psychosom 2016;85:270-288.
69 Mohr DC, Spring B, Freedland KE, Beckner V, Arean P, Hollon SD, Ockene J, Kaplan R: The selection and design of control conditions for randomized controlled trials of psychological interventions. Psychother Psychosom 2009; 78:275-284.

70 Lipowski ZJ: Psychiatry: mindless or brainless, both or neither? Can J Psychiatry 1989; 35:249-254.

71 Hoffmann TC, Del Mar C: Clinicians' expectations of the benefits and harms of treatments, screening and tests. JAMA Internal Med 2017;177:407-419.

72 Fava GA, Cosci F, Offidani E, Guidi J: Behavioral toxicity revisited: iatrogenic comorbidity in psychiatric evaluation and treatment. J Clin Psychopharmacol 2016;36:550-553.

73 Moncrieff J, Cohen D: Rethinking models of psychotropic drug action. Psychother Psychosom 2005;74:145-153. 